\title{
Bölgeler Arası Göçün Yaşlanmaya Etkisi: TÜik İBB2 Verileri Üzerine Ampirik Bir Araştırma
}

\author{
Tekin Akgeyik ${ }^{1}$
}

Öz

Bu araştırmanın amacı, Türkiye'de bölgeler arası göçün yaşlanmaya etkisini analiz etmektir. Veri seti, TÜiK IBB2 düzeyinde 2009-2017 dönemine ait ortanca yaş, toplam doğurganlık hızı, kaba ölüm hızı ve net göç hızı istatistiklerinden oluşmaktadır. Hiyerarşik regresyon analizi bulgularına göre, bölgeler arası net göç yaşlanmanın açıklayıcı değişkenidir. Göç değişkeni ortanca yaştaki değişimi \%35 oranında açıklayabilmektedir. Araştırmada ayrıca kaba ölüm hızı ve toplam doğurganlık oranı yaşlanmanın açıklayıcı diğer değişkenleri olarak tanımlanmıştır. Tüm değişkenler bir arada ortanca yaştaki değişimi \%94,6 oranında açıklayabilmektedir. Araştırmanın bir diğer sonucu, bölgesel yaşlanma ile bölgeler arası göç arasında istatistiki açıdan anlamlı ve pozitif yönlü korelasyon ilişkisi olduğu yönündedir. Nihayet, ANOVA analizleri; ortanca yaş, net göç hızı, kaba ölüm hızı ve toplam doğurganlık oranlarının IBB2 bölgeleri arasında istatistikî olarak anlamlı şekilde farklılaşt̆ğını göstermektedir.

\section{Anahtar Kelimeler}

Göç• Yaşlanma • Ortanca yaş• Doğurganlık hızı • Kaba ölüm hızı

1 Sorumlu Yazar: Tekin Akgeyik (Prof. Dr.), İstanbul Üniversitesi, İktisat Fakültesi, Çalışma Ekonomisi ve Endüstri İlişkileri Bölümü, İstanbul, Türkiye. Eposta: akgeyik@istanbul.edu.tr

Atıf: Akgeyik, T. (2018). Bölgeler arası göçün yaşlanmaya etkisi: TÜík iBB2 verileri üzerine ampirik bir araştırma. Sosyal Siyaset Konferansları Dergisi, 75, 69-91. http://dx.doi.org/10.26650/jspc.2018.75.0009 


\title{
The Impact of Intra-Regional Migration On Aging (An Empirical Study On TSI Data Classified At Statistical Region Level 2)
}

\author{
Tekin Akgeyik ${ }^{1}$
}

\begin{abstract}
This paper investigates the impact of intra-regional migration on aging based on Turkish Statistics Institution (TSI) data classified at Statistical Region Level 2. The results of the hierarchical regression analysis revealed that net migration rate was a significant predictor of regional aging. This predictor accounted for $35 \%$ of the variance in regional aging. Moreover, total fertility rate and crude death rate were observed to predict regional aging. All predictors together explained $94.6 \%$ of the variance in regional aging. The results of correlation analysis indicated that regional aging was positively and significantly correlated with net migration rate and crude death rate, but was negatively and significantly related to total fertility rate. Finally, the ANOVA analysis showed that mean age, total fertility rate, net migration rate, and crude death rate differed significantly between the regions.
\end{abstract}

\section{Keywords}

Migration • Aging $\bullet$ Mean age $\bullet$ Fertility rate $\bullet$ Death rate

1 Corresponding author: Tekin Akgeyik (Prof.), Istanbul University, Faculty of Economics, Department of Labor Economics and Industrial Relations, Istanbul, Turkey. Email: akgeyik@istanbul.edu.tr

To cite this article: Akgeyik, T. (2018). The Impact of Intra-Regional Migration On Aging (An Empirical Study On TSI Data Classified At Statiscal Region Level 2) Sosyal Siyaset Konferansları Dergisi, 75, 69-91. 


\section{Extended Summary}

Migration refers to human movements across geographical boundaries (DPhil, 2000: 7). There are several push-and-pull factors affecting migration. The push factors include low agricultural productivity, lack of employment opportunities, low wages, regional conflict, and natural disasters. The pull factors include urbanization, better employment potential, better working and living conditions, industrialization, and a safer environment. In 2017, the number of international migrants rose to 257 million worldwide, making up 3.4 percent of the world's population (UN (a), 2018).

Population aging means "the process of change in the population's age group structure, in the sense of an increase in the elderly group's ratio to the detriment of the young group, as a visible and long-term trend" (Stoica, 2011: 295). According to UN projections, the percentage of persons aged 60 years or older will increase from $8.3 \%$ in 2017 to $22 \%$ in 2055 .

Population aging is affected by a combination of factors. In empirical studies, low fertility rates and low mortality rates, as well as migration, have been identified as explanatory factors for population aging.

This paper investigates the impact of intra-regional migration on regional aging based on Turkish Statistics Institution (TSI) data classified at Statistical Region Level 2. The paper is structured in three parts. The first part provides a conceptual framework for migration and population aging. The study methodology is explained in the next section. The last section presents the findings of the study.

The data set for this study included median age, total fertility rate, net migration rate across regions, and crude death rate statistics by Regions Level 2, 2009-2017. Median age means the age of the person in the middle when all the persons in the population are sorted in ascending order (TÜIK (b), 2018). Total fertility rate means the average number of live births per between 15 to 49 years of age (TÜİK (e), 2018). Crude death rate means the number of deaths per thousand persons in the current year (TÜIK (c), 2018). Net migration rate means the number of net migration per thousand persons who are able to migrate (TÜIK (d), 2018).

Aging was the dependent variable, which was measured by median age. The independent variables were total fertility rate, crude death rate, and net migration rate across regions.

The study seeks to answer three research questions: (1) Are there statistically significant differences in median age, total fertility rate, crude death rate, and net migration rate across regions? (2) Is there a correlation between the variables? (3) To 
what extent are the independent variables predictors for the number of regional aging?

Descriptive statistics involving the mean values and standard deviations were used to summarize the data. The significant differences were examined by the ANOVA. The Pearson correlation analysis was performed to evaluate the correlations between the variables. Lastly, the study investigated the predictors of aging by using the hierarchical regression analysis.

Overall, the results of the hierarchical regression analysis revealed that net migration rate was a significant predictor of regional aging. This predictor accounted for 35\% percent of the variance in regional aging. Moreover, total fertility rate and crude death rate were observed to predict regional aging. Taken together, all predictors explained $94.6 \%$ percent of the variance in regional aging. The findings are consistent with the findings of Coleman (2008: 463), Chen et al. (2018: 139), Zlotnik, (2011: 99), Ge (1990: 1), and Jahan et al. (2014: 4), who showed that migration was a predictor of population aging. However, it differs from the findings of Shen and Dai (2006: 37), who indicated that migration was not a predictor of population aging.

Secondly, the results of correlation analysis indicated that regional aging was positively and significantly correlated with net migration rate and crude death rate, but was negatively and significantly related to total fertility rate. Moreover, there was a significant and negative relationship between crude death rate and total fertility rate. Finally, the study observed a negative association between total fertility rate and net migration rate.

Furthermore, the ANOVA analysis showed that mean age, total fertility rate, net migration rate, and crude death rate differed significantly between the regions.

In conclusion, based on the findings of the present study, it appears that intraregional migration is a predictor of regional aging. Future research should examine other possible factors affecting regional aging, such as life expectancy at birth, and the environmental and genetic factors relevant to population aging. 


\section{Bölgeler Arası Göçün Yaşlanmaya Etkisi: TÜİK İBB2 Verileri Üzerine Ampirik Bir Araştırma}

Göç insanlık tarihi kadar eski bir olgudur. Arkeolojik bulgular ilk insanların Afrika'dan binlerce yıllık bir dönemde dünyanın her tarafına göç yoluyla dağıldığını ortaya koymaktadır. Tarihsel süreçte büyük imparatorluklar aynı zamanda büyük göçleri de yaratmıştır. Çin, Yunan, Pers, Roma ve Osmanlı imparatorlukları hüküm sürdükleri bölgelerde kitlesel insan hareketliliğine yol açan imparatorluklardır (DPhil, 2000: 4).

Göçler, insanların daha iyi ekonomik ve sosyal koşulları arayışının bir sonucu olarak ortaya çıkmaktadır. Bazı durumlarda ise, göç, güvenlik ihtiyacının bir sonucu olarak zorunlu bir seçenek haline dönüşmektedir. Hangi nedenle olursa olsun göçün ekonomik, sosyal ve politik etkileri olduğu açıktır. Buna karş11ık göç, analizi zor bir alandır. Oldukça kompleks bir olgu olarak göçün yarattığı sonuçları etkileyen çok sayıda değişken mevcuttur. Ayrıca uluslararası göç verileri yetersizdir ve bu nedenle ülkeler arasında karşılaştırmalar yapmak oldukça güçtür (Coleman, 2008: 463).

Göçün birçok demografik etkileri olduğu görülmektedir. Örneğin göç alan bölgelerde göçler nüfus artışının önemli bir kaynağı haline dönüşmektedir. Buna karş11ık göç veren bölgelerde Göçler, yaşıı bağımlılık oranını yükselten bir faktördür. Göçler ayrıca toplumun yaş kompozisyonunun bozulmasına yol açabilmektedir.

Göçün etkilerinden biri de demografik yaşlanmayla ilişkilidir. Yaşlanma modern dünyanın karşı karşıya olduğu en önemli sosyal sorunlardan biridir. Projeksiyonlar yüzyılın sonuna kadar hem gelişmiş hem de gelişmekte olan birçok toplumun yaşlanma sorununun bir parçası olacağını göstermektedir. Toplumsal yaşlanmayı etkileyen birçok faktör mevcuttur. Doğumdaki hayat beklentisinin artması ve doğurganlık oranının azalması yaşlanmaya yol açan ana faktörlerdir. Bu genel koşullara ilave olarak göçlerin de yaşlanmaya yol açan faktörlerden biri olduğu bilinmektedir.

Yaşlanma sadece sosyal değil aynı zamanda ekonomik ve politik sonuçları da olan bir sorun alanıdır. Demografik yaşlanma emeklilik ve sağlık sistemlerinin sürdürülebilirliğini, işgücü piyasalarının fonksiyonelliğini ve toplumların uyum yeteneğini tehdit etmektedir (Zaiceva and Zimmermann, 2014: 2). 
Bu araştırmanın amac1, İBB2 düzeyinde Türkiye'de bölgeler arası göçün yaşlanmaya etkisini analiz etmektir. Veri seti 2009-2017 dönemine ilişkin ortanca yaş, net göç hızı, kaba ölüm hızı ve toplam doğurganlık istatistiklerini kapsamaktadır. Makale üç bölümden oluşmaktadır İlk bölümde araştırmanın kavramsal çerçevesi açıklanmaktadır. İkinci bölümde araştırma yöntemi tanımlanmakta, son bölümde ise, araştırmada ulaşılan bulgular açıklanmaktadır.

\section{Kavramsal Çerçeve}

\section{Göç}

Birleşmiş Milletler'e (BM) göre göç, coğrafi alanlar arasında yer değiştiren insanların hareketliliğini ifade eden bir kavramdır. Aynı ülke sınırları içinde gerçekleşen insan hareketliliğine iç göç denmektedir. Sınır aşan insan hareketliliği ise, uluslararası göç kavramıyla tanımlanmaktadır (DPhil, 2000: 7).

İnsanların göç etmesine yol açan birçok itici ve çekici faktör mevcuttur. İtici faktörler, insanları göç etmeye yönelten etmenlerdir. Sosyal, ekonomik ve politik açıdan olumsuz koşullar insanları yaşadıkları bölgelerden ayrılmaya zorlayabilmektedir. Örneğin, düşük tarımsal verimlilik, istihdam firsatlarının yetersizliği, ücretlerin düşük olması, bölgesel çatışmalar ve doğal afetler itici faktörlerden bazılarıdır. Çekici faktörler ise, insanlara daha iyi yaşam koşulları vaat eden etmenlerdir. Kentleşme, sanayileşme, daha iyi istihdam ve çalışma koşulları, eğitim ve sağlık koşulları, güvenli ve istikrarlı bir ortam çekici faktörler arasındadır (George, 2009: 67).

Ekonomik, sosyal ve politik krizler birçok ülkede hem ülke içi hem de uluslararası göçleri tetikleyici bir rol oynamaktadır. Bu nedenle uluslararası göçler son 20 yıllık dönemde ciddi bir artış göstermiştir. Göçmen sayısı 2000 yılına kıyasla 85 milyon artışla 2017 yılında 257 milyona ulaşmıştır. Bu dönemde göçmenlerin oranı dünya nüfusunun $\% 2,8$ 'inden $\% 3,4$ 'üne ulaşmıştır. 2000-2017 dönenimde yapılan göçlerin \%63'ü yüksek gelirli ülkelere gerçekleşirken, göçmenlerin \%48,4'ü, kadındır (UN (a), 2018).

Göçmen sorununun en fazla yaşandığı bölge Kıta Avrupa'sıdır. Nitekim 2017 y1lı sonu itibariyle Batı Avrupa ülkelerinde göçmenlerin toplam nüfusa oranı \%14'ü aşmıştır. Kuzey Avrupa ülkeleri arasında bu oran \%13 düzeyindedir. Güney Avrupa ülkeleri görece daha iyi bir konumdadır (\%10,5). Ülke düzeyinde ise, Almanya (\%14,8), Norveç (\%15,1) ve İrlanda $(\% 16,9)$ Avrupa 
ortalamasının üzerinde göçmen oranına sahip ülkelerdir (UN (a), 2018). BM projeksiyonlara göre, bu ülkelerde yabancı kökenlilerin toplam nüfusa oranı 2055 yılında \%30 düzeyine ulaşacaktır (Coleman, 2008: 463).

İç göçler de birçok ülkede ciddi boyutlara ulaşmaktadır. UNDP'in tahminlerine göre küresel ölçekte 740 milyon kişi iç göçlerle yer değiştirmektedir (Skeldon, 2017: 2). Bu göçlerin önemli bir kısmının gelişmekte olan ülkelerde yaşandığ1 açıktır. Örneğin iç göçler Hindistan'da nüfusun \%30’una ulaşmaktadır. Brezilya ve Çin gibi gelişmiş ülkelerle kıyaslandığında göç oranı açısından Hindistan'ın yüksek bir iç göç oranına sahip olduğu görülmektedir. Hindistan'da iç göçlerin en az \%65'i aynı bölge içinde gerçekleşmek ve en az yarısı evlenme amacıyla kadınların yaptığı göçlerden oluşmaktadır. Hindistan'da bölgeler arası göç oranı \%2,8 düzeyinde kalmaktadır. Bu oran Brezilya (\%9) ve Çin'de (\%10) daha yüksektir. Hindistan ayrıca eyaletler arası iç göçler $(\% 1)$ açısından da Brezilya $(\% 3,6)$ ve Çin'den $(\% 4,7)$ daha iyi bir konumdadır (Kone ark., 2018: 729).

Bu konuda en çarpıcı örneklerden biri Çin'dir. Bu ülkede son 30 yıllık dönemde ekonomik reformlarla birlikte artan kentleşme ve modernleşme süreci bölgeler arası göçe ciddi bir ivme kazandırmıştır. Çin'de 2000 yılında 121 milyon olan bölgeler arası göç 2010 yılında 221 ve 2016 yılında 245 milyona ulaşmıştır. Bu dönemde iç göçlerin toplam nüfusa oranı \%16,3'ten \%17,5'e yükselmiştir (Chen ark., 2018: 133).

İç göçler gelişmiş ülkelerde de ciddi bir sorun olma eğilimindedir. Örneğin ABD'de 2016-2017 döneminde nüfusun \%10,6's1 (33,6 milyon) ülke içinde göç etmiştir. Göç edenlerin \%19'u farklı bir eyalete göç ederken, büyük bir bölümü (\%64) aynı eyalette yer değiştirmeyi tercih etmiştir. ABD'de aynı dönemde 1,3 milyon kişi de yurtdışına göç etmiştir (US Census, 2018). İngiltere'de ise, ülkede iç göçler istikrarlı bir şekilde artmaktadır. 2008 yılında 2,63 milyon olan göç, sonraki 10 yılda \%22 artışla 3,2 milyon ulaşmıştır. Söz konusu dönemde iç göçlerin toplam nüfusa oranı \%4,2'den \%4,8'e çıkmıştır (ONS, 2018: 15).

Göçün Türkiye'de de ciddi boyutları olan bir sorun alanı olduğu açıtır. Adrese Dayalı Nüfus Kayıt Sistemi verilerine göre, 2013-2017 döneminde Türkiye'de göç eden nüfus 13 milyona ulaşmıştır. Ortalama her yıl 2,6 milyon kişi bulunduğu bölgeyi terk ederek başka illere göç etmektedir. Göçlerin 
büyüklüğü, 2013-2017 döneminde 78,7 milyon olan ortalama Türkiye nüfusunun \%3,3'üne karş1lık gelmektedir.

Göç, sosyal, kültürel ve ekonomik açıdan ciddi etkileri olan önemli bir sosyal olgudur. Bu etkiler hem göç veren bölgeler hem de göç alan bölgeler açısından farklı biçimlerde gerçekleşmektedir. Etkinin boyutları göçün niteliği, göç edenlerin profili ve göçün süresi gibi değişkenlere bağlı olarak ortaya çıkmaktadır (DPhil, 2000: 18).

\section{Demografik Yaşlanma}

Demografik yaşlanma, toplam nüfus içinde 60 ve üstü yaş grubunun oransal ağırlığının artmasıdır. Toplumsal yaşlanma uzun bir süreçte gerçekleşen demografik bir olgudur. Demografik yaşlanmaya yol açan başat faktör doğurganlık oranının gerilemesidir. Ayrıca doğuşta beklenen yaşam süresinin artması ve göçler, toplumların yaşlanma sürecine girmesine yol açan diğer nedenlerdir. Demografik yaşlanma süreci sayısal analizlerle ortaya konmaktadır. Toplam nüfus içindeki yaşlı nüfusun oranı ve demografik yaşlanma indeksi bu amaçla kullanılan araçlardır (Stoica, 2011: 295).

BM verilerine göre, küresel ölçekte 2012 yılında 810 milyon olan 60 ve daha yaşıı nüfus 2050 yılında 2 milyara ulaşacaktır. Dolayısıyla halen küresel nüfus içinde $\% 8,3$ olan 60 ve üstü yaş grubunun 2050 yılında \%22'ye yükseleceği tahmin edilmektedir. 2055 yılında insanlık tarihinde ilk defa yaşlı nüfusun oranı $(\% 22,2)$ 0-14 yaş grubundaki çocuk nüfusu oranını $(\% 20,9)$ aşmış olacaktır. Gelişmekte olan ülkelerde yaşlanmanın tahmin edilenden daha hızlı bir süreçte gerçekleşmesi küresel yaşlanmanın ivme kazanmasına yol açmaktadır (Zaiceva and Zimmermann, 2014: 2).

Yaşlanma problemi özellikle gelişmiş ülkelerde daha ciddi bir sorun olma eğilimindedir. Örneğin Kıta Avrupa'sında 2015 yılında \%23,9 düzeyinde olan yaşlı nüfusunun yüzyılın sonuna kadar 11,9 puan artışla \%35,8 çıkması beklenmektedir. Sorun bazı ülkelerde daha güçlü yaşanmaktadır. Nitekim İtalya'da kadın başına doğurganlık 1,2 çocuğa gerilerken, emeklilerin çalışanlara oranı \%70'leri aşma eğilimdedir. Bu ülkede 2050 y1lında 65 ve üstü yaş grubunun toplam nüfus içindeki oranı \%40,3'e ulaşacaktır (Zaiceva and Zimmermann, 2014: 2).

BM projeksiyonlarına göre, Japonya'da 2015 yılında \%26 olan yaşlı nüfusu 2055 'te \%36,7 ile zirveye ulaşacak daha sonra oldukça yavaş bir azalma 
trendini girecektir. Buna karşılık Yüzyılın sonunda da yaşlı nüfusu \%35'in üzerinde kalmaya devam edecektir (UN (b), 2018).

Doğurganlık ve göç oranının yüksek olduğu ABD'de sorun henüz Kıta Avrupa'sında yaşandığ 1 ölçüde ciddi boyutlara ulaşmamıştır. Bu ülkede \%20,6 düzeyinde olan yaşlı nüfusun 2050 yılında \%28,3'e ulaşması beklenmektedir (UN (b), 2018).

Türkiye'de ise, 2015 yılında \% 7,8 olan yaşlı nüfus oranı 2,6 katlık bir artışla 2050 yılında \%20,6'ya ulaşacaktır (BM (b), 2018). Ayrıca TÜİK ortanca yaş verileri demografik yaşlanmanın seyrini açıkça ortaya koymaktadır. Örneğin 2007-2017 dönemine Türkiye' de ortanca yaş 28,3'ten 3,4 katlık bir artışla 32,1'e yükselmiştir. 2017'de ortanca yaş Sinop ve Balıkesir'de 39'u aşmıştır. Buna karşılık Şanlıurfa, Ağrı ve Şırnak'ta 21'in altındadır. 2007-2017 dönemine ortanca yaş en çok Ordu $(6,4)$, Yozgat $(6,2)$ ve Giresun'da $(6,1)$ artmıştır. Şanlıurfa $(1,3)$, Kilis $(1,7)$ ve Gaziantep $(1,8)$ ise, ortanca yaşın en az arttığı illerdir (TÜİK (b), 2018).

\section{Göçün Demografik Etkileri}

\section{Yaşlanma}

Göçün demografik yaşlanmayı etkileyen önemli bir faktör olduğu açıktır. Özellikle doğurganlık oranının ve ölüm hızının gerilediği bölgelerde göç toplumsal yaşlanmanın düzeyini belirleyen başat faktörlerden biridir (Chen ark., 2018: 133).

Göçlerin toplumsal yaşlanmaya etkisi birçok araştırmacı tarafından hem uluslararası hem de iç göç bağlamında analiz edilmiştir. Örneğin Coleman göçlerin $\mathrm{AB}$ ülkelerinde yaşlanmaya olası etkilerini incelemiştir. Araştırmacıya göre, göçler alıcı ülkenin ortalama yaşını düşürmektedir. Buna karşılık araştırmacı katlanarak artan kitlesel göçler dışında mevcut göç trendlerinin nüfusun yaşlanma sorununu kalıcı olarak çözemeyeceği görüşündedir (Coleman, 2008: 463).

Chen ark. (2018: 139) tarafından yapılan bir araştırmada ise, Çin'de 287 il örneklemi bağlamında 2000-2010 döneminde gerçekleşen kitlesel iç göçlerin yaşlanmaya etkisi analiz edilmiştir. Sonuçlar, yaşlanmanın kitlesel göçlerden büyük 
ölçüde etkilendiğini göstermektedir. Araştırmaya göre, göçler nedeniyle örneklem kapsamındaki illerde 2000-2010 döneminde yaşlı şehirlerin (65 ve daha yaşlı nüfusun toplam nüfusun \%7'sini aştığı iller) oranı \%50'den \%90'na çıkmıştır.

Chen'in araştırma bulguları, bölgeler arasında görülen yaşlanma profili farklılıklarının 2000 yılından sonraki dönemde değişim trendine girdiğini göstermektedir. Örneğin bölgeler arasında yaşlanma oranındaki farklılıklar büyük ölçüde daralmıştır. Veriler, demografik olarak en yaşlı illerin göç veren Kuzeydoğu bölgelerinde olduğunu, buna karşıllk göç alan Doğu bölgelerindeki illerin kısmen daha iyi durumda olduğuna işaret etmektedir (Chen ark., 2018: 132).

Zlotnik (2011) ise, Avustralya, Belçika, Kanada, Fransa, Almanya ve İsveç örneklemi kapsamında II. Dünya Savaşı sonrası dönemde gerçekleşen uluslararası göçlerin toplumsal yaşlanmaya etkisini araştırmıştır. Bulgular, 30 yıldan uzun süren bir dönemde istikrarlı uluslararası göçün örneklem kapsamındaki ülkelerde nüfusun yaşlanmasını azaltmada etkili bir faktör olduğuna işaret etmektedir. Araştırmaya dâhil edilen 6 ülke arasında göçlerin yaşlanmayı en fazla yavaşlattığı ülke Avustralya'dır. Bu ülkede 1946-1981 dönemindeki göçler medyan yaşı 1,5 yıl geriletmiştir. Gerileme Kanada, Fransa ve Almanya'da 0,5 yaşla sınırlıdır. Belçika and İsveç’te ise, görece daha yüksek bir gerileme yaşanmıştır (0,7 yaş) (Zlotnik, 2011: 99).

Zlotnik'e göre, toplumsal yaşlanma açısında göçün bir diğer etkisi, 65 ve üstü nüfusun oranını azaltmış olmasıdır. Sözgelimi, Avustralya' da göçler yaşlı nüfusun toplam nüfus içindeki payını $\% 2$ düzeyinde azaltmıştır. İsveç’te ise, gerileme $\% 1$ düzeyindedir. Etkinin en sınırlı kaldığı ülke Almanya'dır. Göçler bu ülkede yaşlı nüfusun oransal ağırlığını sadece \%0,5 düzeyinde azaltmıştır. Altı ülke bir arada ele alındığında göçlerin 65 ve üstü yaş grubundaki nüfusun oranını \%1 düzeyinde azatlığı görülmektedir (Zlotnik, 2011: 99).

Ge (1990: 1) konuyu karşılaştırmalı olarak Çin ve Japonya örneklemleri bağlamında sorgulamıştır. Araştırmacı, Çin'de Güneydoğu kıyı bölgesinde yaşlanmanın kitlesel işgücü göçünün bir sonucu olarak azaldığını buna karşılık göç veren Merkezi ve Batı bölgelerinde yaşlanmanın daha ciddi bir soruna dönüştüğü sonucuna ulaşmaktadır.

Ge, daha sınırlı ölçüde olmak üzere Japonya'da da göçlerin bölgesel yaşlanma üzerinde etkili olduğunu tespit etmiştir. Japonya'da ağırlıklı olarak 
25-35 yaş grubunu etkileyen göçlerin kırsaldan metropol alanlara yöneldiğini belirten Ge, bunun göç veren bölgelerde toplumsal yaşlanmayı olumsuz etkilediğini gözlemlemiştir. Araştırmacıya göre, daha fazla göç alan bölgelerde yaşlanma görece daha düşük bir hızda seyretmektedir (Ge, 1990: 8).

Göçlerin yaşlanmaya etkisini analiz eden bir diğer araştırmacı Jahan'dır (2014). Malezya'da ulusal ve eyalet düzeyindeki nüfus verileri kullanılarak gerçekleştirilen araştırmanın bulguları, kentleşme sürecinin kaçınılmaz bir sonucu olarak bölgeler arası göçün toplumsal yaşlanmaya güçlü şekilde etkilediği yönündedir (Jahan ark., 2014: 4).

Öte yandan Shen ve Dai (2016) göçlerin yaşlanmaya etkisinin düşüldüğü kadar yüksek olmadığı görüşündedirler. Araştırmacılar çalışmalarında Çin ana kıtasından gelen göçlerin Hong Kong'da yaşlanma sorununu hafiflettiği varsayımını sorgulamışlardır. Sonuçlar, bu varsayımın gerçekçi olmadığını ve göçün yaşlanmayı etkilemediği yönündedir. Shen ve Dai’ye göre, yaşlanmaya etkisi açısından büyüklüğü yanında göçün zamanlaması da önemli bir faktördür. Araştırmacılar, göçün ancak yaşlanma problemi ciddi boyutlara ulaştığında etkili bir çözüm aracı olabileceğini ileri sürmektedirler (Shen and Dai, 2006: 37).

\section{Diğer Demografik Etkileri}

Göç, demografik yaşlanmayı dolaylı olarak etkileyen başka sonuçlar da yaratmaktadır. Göçün bu etkileri birçok ampirik araştırmada incelenmiştir. Örneğin göçlerin $\mathrm{AB}$ ülkelerindeki demografik etkileri geniş bir projeksiyonda Coleman tarafindan analiz edilmiştir. Coleman, göçlerin Avrupa ülkelerinde demografik profili değiştirdiği ve bu değişimin Yüzyılın sonuna kadar devam edeceği düşüncesindedir. Araştırmacı bu etkilerden birinin doğurganlık oranı olduğuna işaret etmektedir. Göçler bazı ülkelerde doğurganlık oranını olumlu yönde etkilemektedir. Örneğin göçlerin bir sonucu olarak 2001 ile 2006 yılları arasında İngiltere ve Galler'de toplam doğurganlı oranı 1,63'ten 1,86'ya yükselmiştir (Coleman, 2008: 459). İngiltere'de göçlerin nüfus artışına katk1s1 \%59 düzeyine ulaşmıştır. Bu ülkede nüfus artışının sadece \%41'i doğurganlıkla sağlanmaktadır (ONS, 2018: 4).

Coleman araştırmasında göçlerin nüfus artışına etkisini de analiz etmiştir. Araştırmacı göçler nedeniyle 2055 yılında kadar bazı Kuzey Batı Avrupa ülke- 
lerinde hızlı bir nüfus artışı yaşanacağını buna karşılık nüfus artışının Güney ülkelerinde dikkat çekici şekilde yavaşlayacağını öngörmektedir. Coleman'a göre, göçlerin yıkıcı etkisi en çok Doğu Avrupa ülkelerini etkileyecektir. Nitekim Polonya, Litvanya, Bulgaristan ve Romanya gibi ülkelerin 2055 yılında nüfuslarını $\% 15$ ile \%27 oranında kaybetmesi beklenmektedir (Coleman, 2008: 459).

Konuyu AB ülkeleri bağlamında analiz eden bir diğer çalışma Philipov ve Schuster (2010: 3) tarafından yapılmıştır. Araştırmacılar, AB üyesi ülkelerde göçün nüfusun hacmine ve yaş kompozisyonuna önemli etkileri olacağ 1 iddiasındadırlar. Analizde İspanya, Fransa, Avusturya ve Almanya'da göçün bir sonucu olarak nüfusun önemli ölçüde artacağı, buna karşılık Portekiz ve Bulgaristan'da nüfusun gerileyeceği sonucuna ulaşılmıştır. Göçün Merkezi Avrupa ülkelerinde, nüfus artışına katkısının daha sınırlı düzeyde kalacağı öngörülmüştür. Kuzey Avrupa ülkelerinin ise, 2000'li yıllarda göç veren ülke konumundan uzaklaşarak göç alan ülkeler haline geldikleri gözlenmiştir (Philipov and Schuster, 2010: 3).

Göçün yaş kompozisyonuna etkisini inceleyen bir diğer araştırma Anghel ark. tarafından 2016 yılında Romanya'da yapılmıştır. Araştırma bulguları, veren bölgeler açısından göçün negatif etkilerini açıkça ortaya koymaktadır. Nitekim göç veren bölgelerde 2000 ile 2009 yılları arasında 14 ve daha küçük yaş grubundaki nüfusun oranı \%21,5 düzeyinde azalmıştır. Ayrıca göç edenlerin ortalama yaşının 34,6 olduğu ve bunların \%62'isinin doğurganlık çağında olduğu tespit edilmiştir (Anghel ark., 2016: 27).

Romanya örneklemi kapsamında bir diğer çalışma Nae (2013) tarafından yapılmıştır. Araştırmacı, 1990 ile 2010 yılları arasında Romanya'dan diğer ülkelere yapılan uluslararası göçün doğurganlık üzerinde yarattığı etkileri analiz etmiştir. Bulgular, uluslararası göçler nedeniyle Romanya'da nüfusun 2,14 milyon azaldığını ve doğurganlık oranının bu dönemde \%o13,7'ten \%o10'a gerilediğini ortaya koymaktadır. Romanya'dan gerçekleşen göçlerin \%56's1nın 26-40 yaş grubunda olduğunu kaydeden araştırmacı bunun yaratacağı demografik sonuçlara işaret etmektedir. Nitekim göçler nedeniyle Romanya'da doğurganlık periyodu daralmış ve ilk çocuk için annelik yaşı 22,3'ten 26'ya yükselmiştir (Nae, 2013: 37). 


\section{Yöntem}

\section{Veri Seti}

Veri seti, TÜİK IBB2 düzeyinde 2009-2017 dönemine ait ortanca yaş, toplam doğurganlık hızı, kaba ölüm hızı ve net göç hızı istatistiklerinden oluşmaktadır.

Ortanca yaş, nüfusu oluşturan kişilerin yaşları, küçükten büyüğe doğru s1ralandığında ortada kalan kişinin yaşını tanımlamaktadır (TÜíK (b), 2018). Toplam doğurganlık hızı, bir kadının 15-49 yaşları arasında doğurabileceği ortalama canlı doğan çocuk sayısını ifade etmektedir (TÜİK (e), 2018). Kaba ölüm hızı, belli bir yılda her bin kişi başına düşen ölüm sayısını tanımlamaktadır (TÜİK (c), 2018). Net göç hızı ise, göç edebilecek her bin kişi için net göç sayısını ifade etmektedir (TÜIKK (d), 2018).

\section{Örneklem}

Örneklem grubu TÜİK IBB2 sınıflamasında yer alan bölgelerden oluşmaktadır. IBB2 sınıflamasında 26 bölge bulunmaktadır. Bölge kodları ve bölgelerde yer alan iller Tablo 1'de gösterilmiştir.

Tablo 1

TÜIK IBB2 sinıflamast

\begin{tabular}{llll}
\hline $\begin{array}{l}\text { Bölge } \\
\text { Kodu }\end{array}$ & Kapsadığı İller & Bölge & Kapsadı̆̆ı İller \\
\hline TR10 & İstanbul & TR71 & Kırıkkale, Aksaray, Niğde, Nevşehir, Kırşehir \\
TR21 & Tekirdağ, Edirne, Kırklareli & TR72 & Kayseri, Sivas, Yozgat \\
TR22 & Balıkesir, Çanakkale & TR81 & Zonguldak, Karabük, Bartın \\
TR31 & İzmir & TR82 & Kastamonu, Çankırı, Sinop \\
TR32 & Aydın, Denizli, Muğla & TR83 & Samsun, Tokat, Çorum, \\
TR33 & Manisa, Afyon, Kütahya, Uşak & TR90 & Trabzon, Ordu, Giresun, Rize, Artvin, Gümüşhane \\
TR41 & Bursa, Eskişehir, Bilecik & TRA1 & Erzurum, Erzincan, Bayburt \\
TR42 & Kocaeli, Sakarya, Düzce, Bolu & TRA2 & Ağr1, Kars, Iğdır, Ardahan \\
TR51 & Ankara & TRB1 & Malatya, Elazığ, Bingöl \\
TR52 & Konya, Karaman & TRB2 & Van, Muş, Bitlis, Hakkâri \\
TR61 & Antalya, Isparta, Burdur & TRC1 & Gaziantep, Adıyaman, Kilis \\
TR62 & Adana, Mersin & TRC2 & Şanlıurfa, Diyarbakırı \\
TR63 & Hatay, K.Maraş, Osmaniye & TRC3 & Mardin, Batman, Şırnak, Siirt \\
\hline
\end{tabular}

\section{Değişkenler}

Araştırmanın bağımlı değişkeni yaşlanmadır. Yaşlanma ortanca yaştaki değişimle ölçülmüştür. Bağımsız değişkenler ise, toplam doğurganlık hızı, kaba ölüm hızı ve net göç hızı verilerinden oluşmaktadır. 


\section{Araştırma Soruları}

Araştırma üç temel soruyu yanıtlamayı hedeflemektedir: (1) Bağımlı ve bağımsız değişkenler IBB2 bölge düzeyinde istatistikî olarak anlamlı şekilde farklılaşmaktadır mıdır? (2) Bağımlı ve bağımsız değişkenler arasındaki korelasyon ilişkisinin yönü ve gücü nedir? (3) Doğurganlık hızı, kaba ölüm hızı ve net göç hızı ortanca yaştaki değişimi ne ölçüde açıklamaktadır?

Tablo 2

Betimleyici istatistikler

Değişkenler

Bölge Kodu Ortanca Yaş Net Göç Hızı Kaba Ölüm Hızı Toplam Doğurganlık Hızı

\begin{tabular}{|c|c|c|c|c|c|c|c|c|}
\hline & Ort. & S.S. & Ort. & S.S. & Ort. & S.S. & Ort. & S.S. \\
\hline TR10 & 30,9 & 0,9 & 2,9 & 4,2 & 4,1 & 0,1 & 1,8 & 0,1 \\
\hline TR21 & 35,7 & 0,9 & 11,2 & 3,5 & 6,7 & 0,1 & 1,7 & 0,1 \\
\hline TR22 & 37,6 & 1,1 & 4,1 & 4,6 & 8,2 & 0,4 & 1,6 & 0,1 \\
\hline TR31 & 34,5 & 1,1 & 4,5 & 1,7 & 5,8 & 0,3 & 1,6 & 0,1 \\
\hline TR32 & 34,8 & 1,2 & 4,6 & 3,5 & 6,1 & 0,3 & 1,8 & 0,1 \\
\hline TR33 & 33,6 & 1,1 & $-2,2$ & 2,5 & 6,9 & 0,3 & 1,8 & 0,0 \\
\hline TR41 & 33,3 & 1,1 & 6,4 & 1,4 & 5,8 & 0,1 & 1,8 & 0,1 \\
\hline TR42 & 32,8 & 0,9 & 8,7 & 2,8 & 5,3 & 0,2 & 1,9 & 0,1 \\
\hline TR51 & 32,1 & 0,9 & 7,5 & 2,7 & 4,5 & 0,1 & 1,7 & 0,0 \\
\hline TR52 & 30,3 & 1,0 & $-1,3$ & 1,9 & 5,2 & 0,2 & 2,2 & 0,0 \\
\hline TR61 & 34,1 & 1,2 & 7,8 & 2,3 & 4,9 & 0,2 & 1,9 & 0,0 \\
\hline TR62 & 30,3 & 1,1 & $-3,0$ & 1,5 & 4,7 & 0,2 & 2,2 & 0,1 \\
\hline TR63 & 27,6 & 1,0 & $-4,3$ & 1,7 & 4,4 & 0,2 & 2,6 & 0,1 \\
\hline TR71 & 31,3 & 1,1 & $-5,8$ & 5,7 & 5,8 & 0,2 & 2,0 & 0,1 \\
\hline TR72 & 30,6 & 1,4 & $-5,1$ & 1,5 & 5,7 & 0,3 & 2,1 & 0,1 \\
\hline TR81 & 35,4 & 1,2 & $-4,6$ & 3,7 & 6,8 & 0,3 & 1,6 & 0,1 \\
\hline TR82 & 37,1 & 1,2 & 0,4 & 9,3 & 9,3 & 0,3 & 1,7 & 0,1 \\
\hline TR83 & 33,9 & 1,6 & $-6,4$ & 4,2 & 6,7 & 0,3 & 1,8 & 0,0 \\
\hline TR90 & 34,3 & 1,3 & $-2,2$ & 8,8 & 6,7 & 0,4 & 1,8 & 0,0 \\
\hline TRA1 & 28,4 & 1,0 & $-10,8$ & 5,6 & 5,6 & 0,2 & 2,3 & 0,1 \\
\hline TRA2 & 24,6 & 0,9 & $-21,9$ & 3,8 & 4,5 & 0,3 & 3,3 & 0,2 \\
\hline TRB1 & 29,2 & 1,2 & $-4,1$ & 2,2 & 5,2 & 0,1 & 2,1 & 0,0 \\
\hline TRB2 & 20,6 & 1,0 & $-15,9$ & 6,6 & 3,5 & 0,3 & 3,5 & 0,2 \\
\hline TRC1 & 24,8 & 0,7 & $-2,6$ & 0,7 & 4,0 & 0,1 & 3,0 & 0,1 \\
\hline TRC2 & 20,5 & 0,6 & $-6,8$ & 1,5 & 3,4 & 0,2 & 3,8 & 0,1 \\
\hline TRC3 & 19,9 & 0,9 & $-9,4$ & 5,2 & 3,2 & 0,2 & 3,6 & 0,2 \\
\hline Türkiye Ort. & 30,7 & 5,1 & $-1,9$ & 8,6 & 5,5 & 1,4 & 2,2 & 0,7 \\
\hline $\mathrm{P}$ & \multicolumn{2}{|c|}{, 000} & \multicolumn{2}{|c|}{, 000} & \multicolumn{2}{|c|}{, 000} & \multicolumn{2}{|c|}{, 000} \\
\hline \multicolumn{9}{|c|}{ Ort.: Ortalama; S.S.: Standart Sapma } \\
\hline
\end{tabular}




\section{Normallik Testi}

Uygun analiz yöntemini belirlemek amaciyla normallik testi (Kolmogorov-Smirnov) gerçekleştirilmiştir. Ortanca yaş bağımlı değişkeninin çarpıklık $(-, 794)$ ve basıklık $(-, 205)$ değerleri $-1,5$ ve $+1,5$ güven sınırları içinde olmadığından verilerin normal dağılmadığı sonucuna varılmıştır. İkinci aşamada Lg10 dönüştürme işlemi uygulanarak çarpıklık $(-1,101)$ ve basıklık $(, 340)$ değerlerinin normal dağılım değerlerine ulaşması sağlanmıştır.

\section{Veri Analizi}

Betimleyici istatistikler, bağımlı ve bağımsız değişkenlerin ortalama ve standart değerlerini analiz etmede kullanılmıştır. ANOVA ile bölgeler arasındaki farklılık analizleri gerçekleştirilmiştir. Araştırmanın bağımlı ve bağımsız değişkenleri arasındaki ilişkinin gücü ve yönü Pearson korelasyon analizi ile ölçülmüştür. Nihayet, yaşlanmayı etkileyen faktörleri tanımlamada hiyerarşik regresyon analizi kullanılmıştır.

\section{Sonuçlar}

\section{Betimleyici İstatistikler}

Tablo 2'de bağımlı ve bağımsız verilere ilişkin betimleyici istatistikler özetlenmektedir. Değişkenlerin bölgeler arasında ne ölçüde farklılaştı̆̆ını s1namak amaciyla ANOVA testi kullanılmıştır.

Ortanca yaş bölgeler arasında belirgin biçimde farklılaşmaktadır. 20092017 döneminde Türkiye'de ortanca yaş 30,7'dir. Türkiye ortalamasının üzerinde ortanca yaşa sahip 15 bölge bulunmaktadır. Veriler, ortanca yaşın en yüksek olduğu bölgenin Balıkesir ve Çanakkale illerini kapsayan TR22 $(37,6)$ olduğunu göstermektedir. Bu bölgedeki ortanca yaş $(37,6)$ Türkiye ortalama-

Tablo 2

Korelâsyon analizinin sonuçlart

\begin{tabular}{lcccc}
\hline Değişkenler & $\begin{array}{c}\text { Ortanca } \\
\text { Yaş }\end{array}$ & $\begin{array}{c}\text { Toplam } \\
\text { Doğurganlık Hızı }\end{array}$ & $\begin{array}{c}\text { Kaba Ölüm } \\
\text { Hızı }\end{array}$ & $\begin{array}{c}\text { Net Göç } \\
\text { Hızı }\end{array}$ \\
\hline Ortanca Yaş & - & & & \\
Toplam Doğurganlık Hızı &,$- 954^{* *}$ & - & & \\
Kaba Ölüm Hızı &, $798^{* *}$ &,$- 699^{* *}$ & - & \\
Net Göç Hızı &, $592^{*}$ &,$- 606^{* *}$ &, $301^{* *}$ & - \\
\hline$* * 0.01$ düzeyinde anlamlı (İki-yönlü). & & &
\end{tabular}


sindan \%22,4 daha yüksektir. TR82 $(37,1)$, TR21 $(35,7)$ ve TR81 $(35,4)$, Türkiye ortalamasının oldukça üzerinde ortanca yaşa sahip olan diğer bölgelerdir.

Türkiye ortalamasının $(30,7)$ altında ortanca yaşa sahip bölge sayısı 11'dir. En düşük ortanca yaşa TRC3 $(19,9)$ bölgesi sahiptir. Bu bölgedeki ortanca yaş Türkiye ortalamasına göre \%35 oranında daha düşüktür. Türkiye ortalamasına kıyasla belirgin şekilde düşük ortanca yaşa sahip diğer iller, TRC1 $(24,8)$, TRA2 $(24,6)$, TRB2 $(20,6)$ ve TRC2 $(20,5)$ bölgelerinde yer almaktadır.

Toplam doğurganlık oranı da bölgeler arasında istatistiki olarak anlamlı şekilde farklılaşmaktadır. 2009-2017 döneminde Türkiye'de kadın başına düşen çocuk sayısı 2,2'dir. 7 bölgede kadın başına düşen çocuk sayısı Türkiye ortalamasından daha yüksektir. Kadın başına çocuk sayısının en yüksek olduğu bölge 3,8 çocuk ile TRC2'dir. Kadın başına 3'ten fazla çocuğun olduğu diğer bölgeler TRC3 $(3,6)$, TRB2 $(3,5)$ ve TRA2'dir $(3,3)$. Doğanlık oranının en düşük olduğu bölgeler ise, kadın başına 1,6 çocukla TR81, TR22 ve TR31'dir.

Bölgeler arasından belirgin farklılaşmanın kaba ölüm hızı açısından da yaşandığ1 görülmektedir. Referans dönemde Türkiye'de ortalama kaba ölüm hızı \%05,5 düzeyinde gerçekleşmiştir. TR82 bölgesinde kaba ölüm hızı $(\% 09,3)$ Türkiye ortalamasından \%70 daha yüksektir. Kaba ölüm hızının Türkiye ortalamasına kıyasla çok daha yüksek olduğu bir diğer bölge \% 8,2 oranıyla TR22'dir. Kaba ölüm hızının en düşük olduğu iller TRC3 $(\% 03,2)$ bölgesinde yer almaktadır. Bu bölgede kaba ölüm hızı genel ortalamadan \%41 daha düşüktür. Kaba ölüm hızının \%o4'ün altında olduğu iller TRB2 ve TRC2 bölgelerinde yer almaktadir.

Nihayet, net göç hızı da bölgeler arasında istatistiki olarak anlamlı şekilde farklılaşmaktadır. Net göç hızı referans dönemde Türkiye'de ortalama -\%o1,9 düzeyinde gerçekleşmiştir. Bu dönemde TR21 \%11,2 ile en fazla göç alan olduğu bölge olmuştur. TR42, TR61 ve TR51 net göç hızının \%o7'inin üzerinde olduğu bölgelerdir.

2009-2017 döneminde TRA2 bölgesinde yer alan Ağr1, Kars, Iğdır ve Ardahan en fazla göç veren $(-\% 21,9)$ illerdir. TRA2 bölgesi Türkiye ortalamas1na kıyasla 11,8 kat daha fazla göç vermektedir. TRA1 ve TRB net göç hızının -\%o10’un altında olduğu diğer bölgelerdir. 


\section{Korelâsyon Analizi}

Araştırma değişkenleri arasındaki korelasyon analizi sonuçları Tablo 3 'te görülmektedir. Korelasyon matrisine göre, “ortanca yaş” bağımlı değişkeni tüm bağımsız değişkenlerle istatistiki olarak anlamlı şekilde ilişkilidir.

Beklendiği gibi ortanca yaş ile toplam doğurganlık hızı arasında oldukça güçlü ve negatif yönlü bir korelasyon ilişkisi mevcuttur ( $\mathrm{r}=-.954)$. Bu ilişki, toplam doğurganlık oranının arttığı bölgelerde ortanca yaşın düştüğüne işaret etmektedir. Nitekim en yüksek doğurganlık oranına sahip olan bölgeler (TRC2, TRC3 ve TRB2) aynı zamanda ortanca yaşın da en düşük oldu$\breve{g u}$ illerdir. Buna karşılık doğurganlık oranının en düşük olduğu bölgelerde (TRB81 ve TR22) ortanca yaş en yüksek düzeydedir.

Kaba ölüm hızı ile ortanca yaş arasındaki ilişki pozitif yönlü ve güçlüdür ( $\mathrm{r}=.798)$. Bu sonuç, kaba ölüm hızının arttı̆̆ı bölgelerde yaşlanmanın arttığını göstermektedir. Gerçekten de kaba ölüm hızının en yüksek olduğu $\left(\%{ }_{0} 9,3\right)$ TR82'de ortanca yaş $(37,1)$ en yüksek düzeydedir. Kaba ölüm hızının sadece \%o3,2 olduğu TRC3 bölgesinde ise, ortanca yaş 19,9'a gerilemektedir.

Ayrıca net göç hızı ile ortanca yaş arasında pozitif yönlü bir ilişki gözlenmiştir ( $r=.592)$. Dolayısıyla Net göç hızının daha yüksek olduğu bölgelerde ortanca yaşın yükseldiği anlaşılmaktadır. Örneğin net göç hızının \%o11,2 olduğu TR21 bölgesinde ortanca yaş 35,7'ye çıkmaktadır. Oysa net göç hızının -\%021,9 olduğu TRA2 bölgesinde ortanca yaş 24,6'ya gerilemektedir.

Tablo 4

Hiyerarşik regresyon analizinin sonuçları

\begin{tabular}{|c|c|c|c|c|c|c|c|c|c|}
\hline \multirow{3}{*}{ Bağımsız Değişkenler } & \multicolumn{9}{|c|}{ Bağımlı Değişken: Ortanca Yaş } \\
\hline & \multicolumn{3}{|c|}{ 1. Model** } & \multicolumn{3}{|c|}{ 2. Model $* *$} & \multicolumn{3}{|c|}{ 2. Model $* *$} \\
\hline & $\beta$ & $\mathrm{t}$ & $\mathrm{P}$ & $\beta$ & $\mathrm{t}$ & $\mathrm{P}$ & $\beta$ & $\mathrm{t}$ & $\mathrm{P}$ \\
\hline Sabit & - & 349,7 & 000 & - & 124,2 & 000 & - & 131,2 & 000 \\
\hline Net Göç Hızı &, 592 & 11,1 &, 000 & ,387 & 11,7 &, 000 & ,075 & 3,8 &, 000 \\
\hline Kaba Ölüm hızı & & & & ,681 & 20,7 &, 000 & ,375 & 12,6 &, 000 \\
\hline T. Doğurganlık Oranı & & & & & & &,- 716 & $-27,6$ &, 000 \\
\hline Model İçin P & & 000 & & &, 000 & & &, 000 & \\
\hline $\mathrm{F}$ & & 124,99 & & & 391,39 & & & 1356,12 & \\
\hline Model için $\mathrm{R}^{2}$ & & $\% 35$ & & & $\% 77,2$ & & & $\% 94,6$ & \\
\hline $\mathrm{R}^{2}$ değişim oranı & & $\% 35$ & & & $\% 42,2$ & & & $\% 17,4$ & \\
\hline
\end{tabular}

$* \mathrm{p}<0.05 * * \mathrm{p}<0.01$ 
Öte yandan bağımlı değişkenler arasında da ilgi çekici korelasyon ilişkileri bulunmuştur. Örneğin kaba ölüm hızı ile toplam doğurganlık arasında güçlü ve negatif yönlü ( $r=-.699)$ bir ilişki görülmektedir. Bu ilişki beklenen bir sonuçtur. Kaba ölüm hızının düşmesi özellikle de bebek ölümlerinde son 10 yıllık dönemde gözlenen iyileşme doğal olarak doğurganlık oranını olumlu yönde etkilemiştir. Nitekim TÜİK verilerine göre, 2009 yılında \% 13,9 olan bebek ölüm oranı, 2017 y1lı sonunda \%34 azalarak \%o9,2'ye gerilemiştir. Bu dönemde bebek ölüm oranı en fazla Ege ve Marmara bölgelerinde (\%44) gerilemiştir. Buna karşılık Kuzey Anadolu bölgesindeki illerde gerileme \%11 düzeyinde kalmıştır (TÜİK (a), 2008).

Bir diğer bulgu, toplam doğurganlık oranı ile net göç hızı arasındaki korelasyon ilişkisinin negatif yönlü olmasıdır $(r=-.606)$. Bu sonuç, net göç hızının arttığ illerde toplam doğurganlık oranının gerilediğine işaret etmektedir. Gerçekten de net göç hızının \%o11,2 olduğu TR21 bölgesinde toplam doğurganlık oranı 1,7 çocuğa gerilemektedir.

Nihayet kaba ölüm hızı ve net göç hızı arasındaki korelasyon ilişkisinin pozitif yönlü olduğu gözlenmiştir ( $\mathrm{r}=.301)$. Buna göre net göç hızının arttığı bölgelerde kaba ölüm oranı da artmaktadır. Bu sonuç, net göç hızının daha yüksek olduğu bölgelerde genç nüfus gruplarının göç etmeye daha fazla eğilimli olduğuna işaret etmektedir. Nitekim TÜİK verilerine göre, 2017 yılında göç eden 2,7 milyon kişinin\% 81 'i 40 yaşından gençtir. Ayrıca 20-24 yaş grubundaki nüfus arasında göç oranı \%8,9'a yükselmektedir. 20-40 yaş grubundaki nüfusun \%5,3'ü göç etmektedir. Oysa 60 ve üstü yaş grubun sadece \%1,6's1 göç etmektedir. Dolayısıyla geriye daha yaşlı nüfusun kalması nedeniyle 1000 kişi başına düşen ölüm sayısı yani kaba ölüm hızı yükselmektedir (TÜİK (f), 2018).

\section{Yaşlanmayı Etkileyen Faktörler}

Yaşlanmanın açıklayıcı değişkenlerini analiz etmek amacıyla çoklu hiyerarşik regresyon analizi kullanılmıştır. Çoklu hiyerarşik regresyon analizi her aşamadaki açıklayıcı değişkenlerin bağımlı değişkendeki değişimi ne ölçüde açıklayabildiğini izlemeyi mümkün kılan bir yöntemdir. Ayrıca bu yöntemle analizin her aşamasında beta katsayısının anlamlılık değerindeki değişim de görülebilmektedir. Böylece çoklu hiyerarşik regresyon yöntemiyle her bağımsız değişkenin bağımlı değişken üzerindeki etkisi ayrı ayrı gözlenebilmektedir. 
Yaşlanmanın açıklayıcı değişkenleri belirlemek için, üç adımda gerçekleştirilen hiyerarşik regresyon analizinde; birinci adımda net göç hızı değişkeni, ikinci adımda, kaba ölüm hızı ve son aşamada ise, toplam doğurganlık hızı modele dâhil edilmiştir.

Tablo 4'te görüldüğü üzere ilk aşamada denkleme net göç hızı değişkeni dâhil edilmiştir (yaşlanma $=$ sabit + netgöçhızı). Bulgular, 1. modelin bir bütün olarak istatistiki açıdan anlamlı $(\mathrm{p}<.001)$ olduğunu göstermektedir. Sonuçlar yaşlanmadaki değişimin \%35'inin net göç hızı değişkenindeki değişim ile açıklanabildiğini ortaya koymaktadır. Analizler net göç hızının daha yüksek olduğu bölgelerde yaşlanmanın daha hızlı arttığını ifade etmektedir. Örneğin 2017'de net göç hızı -\%o12,64 oranında gerçekleşen Trabzon, Ordu, Giresun, Rize, Artvin ve Gümüşhane illerini kapsayan TR90 bölgesinde ortanca yaş 36'ya yükselmektedir. Oysa net göç hızının sadece -\%o1,65 olduğu Mardin, Batman, Şırnak ve Siirt illerini kapsayan TRC3 bölgesinde ortanca yaş 21,3'e gerilemektedir. Bu durum, TR90 bölgesinde göçün daha ağırlıklı olarak gençler arasında gerçekleşen bir olgu olduğuna işaret etmektedir. Genç nüfusun göç etmesine bağ olarak geride kalan nüfusun ortanca yaşı doğal seyrinden daha hızlı artmaktadır.

İkinci adımda denkleme net göç hızı ile birlikte kaba ölüm hızı değişkeni dâhil edilmiştir (yaşlanma= sabit+netgöçhızı +kabaölümhızı). Model bir bütün olarak istatistiki açıdan anlamlıdır. Bulgular, ortanca yaştaki değişimin \%77,2'sinin bağımsız değişkenlerdeki değişim ile açıklanabildiğine işaret etmektedir.

İkinci modelde kaba ölüm hız ( $\beta=.681, \mathrm{p}<.001)$ yaşlanmayı açıklayan en güçlü değişken konumundadır. Bu sonuç, kaba ölüm hızının arttığı illerde ortanca yaşın daha hızlı arttığını göstermektedir. Bu sonucun ortaya çıkmasında göçün etkisi yansınamaz. Sözgelimi 2017'de Trabzon, Ordu, Giresun, Rize, Artvin ve Gümüşhane illerini kapsayan TR90 bölgesinde \%о7,3 düzeyinde olan kaba ölüm oranı ve -\%12,64 düzeyinde olan net göç hızı ortanca yaşı 36'ya yükseltmiştir. Bu tür bölgelerde göç faktörü genç nüfusun bölgeyi terk etmesine yol açarken, kaba ölüm hızının da artmasına neden olmaktadır. Sonuçta kaba ölüm hızı bu bölgelerde artarken, bu durum ortanca yaşın yükselmesine dolayısıyla toplumsal yaşlanmanın artmasına neden olmaktadır.

Son aşamada modele net göç hızı ve kaba ölüm hızı ile birlikte toplam doğurganlık hızı değişkeni dâhil edilmiştir (yaşlanma= sabit+netgöçhızı+kabaö lümhızı+toplamdoğurganlıkoranı). Model bir bütün olarak istatistiki açıdan 
anlamlıdır. Sonuçlar, ortanca yaştaki değişimin \%94,6'sının bağımsız değişkenlerdeki değişim ile açıklanabildiğine göstermektedir. Toplam doğurganlık oranının modelin açıklayıcılık oranına katkısı \%17,4 düzeyinde olmuştur.

Üçüncü modelde yaşlanmayı en yüksek oranda açıklayan değişken beklendiği gibi toplam doğurganlık oranıdır $(\beta=-.716, p<.001)$. Bulgular, toplam doğurganlık oranının daha yüksek olduğu illerde ortanca yaşın düştüğünü bunun da yaşlanma sürecini geciktirdiğini göstermektedir. Nitekim 2017 y1lında toplam doğurganlık oranının en yüksek olduğu iki bölge (Şanlıurfa ve Diyarbakır illerini kapsayan TRC2 $(3,73)$ ve Mardin, Batman, Şırnak ve Siirt illerini kapsayan TRC3 $(3,31))$ ortanca yaşın da en düşük olduğu bölgelerdir (sırasıyla 21,4 ve 21,3). Buna karş11ık toplam doğurganlık oranın en düşük olduğu Zonguldak, Karabük ve Bartın illerini kapsayan TR81 $(1,46)$ bölgesinde ortanca yaş 37 ile 26 bölge arasında en üst sıradadır.

\section{Genel Değerlendirme ve Sonuç}

Göçün demografik sonuçlar yanında toplumsal yaşlanma üzerinde de etkiler yarattığı açıktır. Literatürde göçün yaşlanma üzerindeki etkileri konusunda çok sayıda araştırma mevcuttur. Ampirik bulgular, göçün yaşlanmayı etkilediğine işaret etmektedir. Bu araştırma, TÜİK 2009-2017 dönemine ait İBB2 düzeyinde ortanca yaş, net göç hızı, kaba ölüm hızı ve toplam doğurganlık oranı istatistiklerini kullanarak göçün yaşlanmaya etkisini ölçmüştür. Analizler sonucunda ulaşılan araştırma bulgularını özetlemek mümkündür.

Hiyerarşik regresyon analizi bulgularına göre, bölgeler arası göç, yaşlanmanın açıklayıcı değişkenidir. Göç değiş̧keni ortanca yaştaki değişimi \%35 oranında açıklayabilmektedir. Araştırmada ayrıca kaba ölüm hızı ve toplam doğurganlık oranı yaşlanmanın diğer açıklayıcı değişkenleri olarak tanımlanmıştır. Bölgeler arası göç $(, 075)$, kaba ölüm hızı $(, 375)$ ve toplam doğurganlık oranına $(-, 716)$ kıyasla yaşlanma üzerinde daha sınırlı bir etkiye sahiptir. Tüm değişkenler bir arada ortanca yaştaki değişimi \%94,6 oranında açıklayabilmektedir. Bu bulgular, araştırmalarında göçün yaşlanmanın açıklayıcı değişkeni olduğunu gözlemleyen Coleman (2008: 463), Chen ark. (2018: 139), Zlotnik, (2011: 99), Jahan ark. (2014: 4) ve Ge'nin (1990: 1) sonuçlarıyla örtüşmektedir. Buna karş11ık sonuçlar, araştırmasında göçün yaşlanma üzerinde etkisi olmadığını tespit eden Shen ve Dai'nin (2006: 37) bulgularından ayrışmaktadır. 
İkinci olarak, korelasyon analizinin sonuçları yaşlanma ile bölgeler arası göç arasında istatistiki açıdan anlamlı ve pozitif yönlü korelasyon ilişkisi olduğunu göstermektedir. Yaşlanma ile pozitif yönlü bir ilişkiye sahip olan bir diğer değişken kaba ölüm hızıdır. Buna karşılık yaşlanma ile toplam doğurganlık oranı arasındaki korelasyon ilişkisi beklendiği gibi negatif yönlüdür.

Öte yandan ANOVA analizleri ortanca yaşın IBB2 bölgeleri arasında istatistikî olarak anlamlı şekilde farklılaştığını göstermektedir. Nitekim 2009-2017 döneminde yaşlanmanın en hızlı gerçekleştiği bölge \%14,1 ile Samsun, Tokat, Çorum ve Amasya illerinden oluşan TR83 bölgesi olurken yaşlanmanın en yavaş gerçekleştiği bölge \%8 ile TR42 (Kocaeli, Sakarya, Düzce, Bolu, Yalova) bölgesi olmuştur.

ANOVA analizleri, ayrıca, kaba ölüm hızı açısından bölgeler arasında istatistikî olarak anlamlı farklılıklar olduğuna işaret etmektedir. Gerçekten de 2009-2017 döneminde TRB2 (Van, Muş, Bitlis, Hakkari) bölgesinde kaba ölüm hızı \%20 oranında gerilerken, bu oran TR90 (Trabzon, Ordu, Giresun, Rize, Artvin, Gümüşhane) bölgesinde \%14,1 oranında yükselmiştir.

ANOVA analizlerinin bir diğer sonucu, net göç hızının bölgeler arasında anlamlı şekilde farklıklaşmasıdır. Örneğin 2009-2017 döneminde net göç hızı İstanbul'da 2009'da \%03,1'den 2017 sonunda -\%00,4'e gerilemiştir. Net göç oranının dikkat çekici bir artış gösterdiği bölge TR32'dir (Aydın, Denizli, Muğla). Bu gölgede net göç oranı \%00,4'ten \%o6,1'ya yükselmiştir.

Nihayet ANOVA analizleri toplam doğurganlık oranının bölgeler arasında farklılaştı̆̆ını ortaya koymuştur. Nitekim 2009-2017 döneminde 26 bölge arasında toplam doğurganlık hızı \%5 oranında düşerek kadın başına çocuk sayısı 2,2'den 2,1'e gerilemiştir. Gerilemenin en fazla görüldüğü bölge TR81'dir (Zonguldak, Karabük, Bartın). Bu bölgede kadın başına düşen çocuk sayısı 1,7'den 1,5'e gerilemiştir. Söz konusu dönemde toplam doğurganlık hızının arttığ 1 tek bölge TR62'dir (Adana, Mersin). TR62'de kadın başına çocuk say1sı 2,1'den 2,2'ye yüksselmiştir.

Sonuç olarak, araştırma bulguları bölgeler arası göçün ortanca yaşın yükselmesine dolayısıyla yaşlanmaya etkisi olduğuna işaret etmektedir. Gelecek araştırmalarda net göç hızı, toplam doğurganlık oranı ve kaba ölüm hızı yanında doğumda hayat beklentisi ve nüfusun yaş kompozisyonu gibi yaşlanmayı etkilemesi muhtemel diğer değişkenlerin açıklayıcı etkisi analiz edilmelidir. 


\section{Kaynakça/References}

Anghel, R. G. and Botezat, A. and Cosciug, A. and Manafi, I. and Roman, M. (2016). "International migration, return migration, and their effects: a comprehensive review on the romanian case”, Munich Personal REPEC Archive.

Chen, R. X., Ping, L., Fen, S. and Peipei. (2018). Internal migration and regional differences of population aging: An empirical study of 287 cities in China, BioScience Trends, 12(2), 132-141.

Coleman, D. (2008). The demographic effects of international migration in Europe, $O x$ ford Review of Economic Policy, 24(3), 452-476.

DPhil, C. M. (2000). Some social and economic consequences of migration, a curriculum paper for Samoa, UNESCO, New Zealand.

Ge, Y. (2014). Impact of internal migration on regional aging in china: With comparison to Japan, www.jcer.or.jp.

George, R. (2009). Adaptation of a tribal community to urban life: An ethnographic study of pardhi immigrants in mumbai, PH.D Thesis, University of Pune, India.

Jahan, N. K., Soyiri, I., Dharmalingam, A., Allotey, P. and Reidpath, D. (2014). Impact of migration and development on population aging in Malaysia: Evidence from Southeast Asian community observatory (SEACO), A Paper Presented in The Population Association of America Annual Meeting, Boston.

Kone, Z. L., Liu, M. Y., Mattoo, A., Ozden, C. and Sharma, S. (2018). Internal borders and migration in India, Journal of Economic Geography, 18(4), 729-759.

Nae, T. R. (2013). Migration and its effects on economic and demographic development in Romania, Mediterranean Journal of Social Sciences, 4(2), 35-43.

Office for National Statistics (ONS). (2018). "Population Estimates for the UK, England and Wales, Scotland and Northern Ireland: Mid-2017”, www.ons.gov.uk.

Philipov, D. and Schuster, J. (2010). Effect of migration on population size and age composition in Europe, Vienna Institute of Demography Paper.

Skeldon, R. (2017). International migration, internal migration, mobility and urbanization: Towards more integrated approaches, United Nations Expert Group Meeting on Sustainable Cities, Human Mobility and International Migration, New York.

Shen, J. and Dai, E. (2006). Population growth, fertility decline, and ageing in Hong Kong, Shanghai-Hong Kong Development institute Occasional Paper No. i4.

Stoica, I. V. (2011). The effects of population aging on rural areas. Case study: The sărăłel hydrographic basin (Buzău Subcarpathians), Analele UniversităNiii din Oradea-Seria Geografi, 21(2), 294-302.

TÜİK (a). (2018). İstatistiki Bölge Birimleri Sınıflaması 1. Düzey ve Cinsiyete Göre Bebek Ölüm Hız1, 2009-2017, tüik.gov.tr.

TÜİK (b), (2018). İllere ve Cinsiyete Göre Ortanca Yaş, 2007-2017, tüik.gov.tr. 
TÜIK (c), (2018). İstatistiki Bölge Birimleri Sınıflamasına Göre Kaba Ölüm Hızı, 20092017, tüik.gov.tr.

TÜİK (d), (2018). İstatistiki Bölge Birimleri Sınıflamasına Göre Net Göç Hızı, 20092017, tüik.gov.tr.

TÜiK (e), (2018). İstatistiki Bölge Birimleri Sınıflamasına Göre Toplam Doğurganlık Hiz1, 2009-2016", tüik.gov.tr.

TÜiK (f), (2018). Yaş Grubu ve Cinsiyete Göre İller Arası Göç Eden Nüfus, 2014-2017, tüik.gov.tr.

UN (a), (2018). Workbook: UN MigrantStock 2017, esa.un.org.

UN (b), (2018). World Population Prospects: The 2017 Revision, esa.un.org.

US Census, (2018). Geographical Mobility: 2016 to 2017, www.census.gov.

Zaiceva, A. and Zimmermann, K. F. (2014). Migration and the demographic shift, IZA Discussion Paper, No. 8743, Bonn.

Zlotnik, H. (2011). International migration and population ageing”, global population ageing: Peril or promise? (Eds. by John R. Beard, Simon Biggs, David E. Bloom, Linda P. Fried, Paul Hogan, Alexandre Kalache, and S. Jay Olshansky), World Economic Forum, 97-102. 